\title{
Adenoid Cystic Carcinoma - A Case Report
}

\author{
G. Lavanya, M. Keerthi, Aruna Kumari, P. Gouri \\ Department of Oral and Maxillofacial Pathology, Kamineni Institute of Dental Sciences, Narketpally, Telangana, India
}

Email for correspondences: dr.lavanya1606@gmail.com

\begin{abstract}
Salivary gland neoplasms of the head and neck comprise of $1-5 \%$ of the total malignancies. Adenoid cystic carcinoma (ACC) is the second most common malignancy of the salivary gland. It is a slow-growing, rare malignant neoplasm of the salivary glands. It carries a poor prognosis due to aggressive nature of tumor and a high rate of recurrence. There is a female preponderance with peak incidence is in the fifth and sixth decades. Palate is the most common site to be involved in the oral cavity. They are usually asymptomatic and characteristically show infiltrative growth and perineural invasion. Perineural invasion along with cranial nerves is a pathognomonic feature of ACC. Surgery is the treatment of choice, but some cases may require radiation therapy after surgery. Rarely, chemotherapy may also be required to control the disease. Here, we present a case report of a 24-year-old female patient with a chief complaint of pain and swelling on the right side of palate for 4 months which was diagnosed histopathologically as a ACC.
\end{abstract}

Key words: Adenoid cystic carcinoma, malignant salivary gland tumor, palate.

\section{INTRODUCTION}

Adenoid cystic carcinoma (ACC) is a malignant salivary gland tumor that was first described by Billroth in 1859 and gave the term cylindroma attributing to its cribriform appearance formed by the tumor cells with cylindrical pseudolumina or pseudospaces. ${ }^{[1]}$ In 1954, Ewing introduced the term "ACC." ACC is a relatively rare malignant salivary gland tumor comprising $<1 \%$ of all malignancies of head and neck, represents $5-10 \%$ of all salivary gland neoplasms, and accounts for $17.7 \%$ of malignant palatal salivary gland tumors. ${ }^{[2,3]}$

Around $55 \%$ of the cases are associated with parotid and submandibular glands, among which the parotid is the most common site of occurrence, ${ }^{[1]}$ whereas 50\% of intraoral ACC occur on the palate. The other less common sites include the lower lip, retromolar tonsillar pillar area, sublingual gland, buccal mucosa, and floor of the mouth. ${ }^{[3]}$ The tumor, most often, exhibits a small size and slower

\begin{tabular}{|l|l|}
\hline Quick Response Code & Article Info: \\
\hline doi: 10.5866/2018.10.10132 \\
\hline $\begin{array}{l}\text { Received: } 26-06-2018 \\
\text { Revised: } 24-07-2018 \\
\text { Accepted: } 20-08-2018 \\
\text { Available Online: } 25-09-2018 \text { (www. } \\
\text { nacd.in)@ NAD, } 2018 \text { - All rights reserved }\end{array}$ \\
\hline
\end{tabular}

growth, which overlies its extensive subclinical invasion and early metastasis making the prognosis questionable. ${ }^{[4]}$ The three histological variants of ACC are cribriform, tubular, and solid, although cribriform is the most common and solid is the least common. Most ACCs do not occur in "pure" cribriform, tubular, or solid types, and they exhibit more than one histopathologic pattern in a single neoplasm. Tumors are classified generally according to the histologic pattern that predominates. Tubular pattern (well differentiated) has the best prognosis compared to cribriform pattern (moderately differentiated) and solid pattern (poorly differentiated). According to Szanto et al., ACC is graded as Grade I (cribriform or tubular), Grade II ( $<30 \%$ solid), and Grade III ( $>30 \%$ solid). ${ }^{[5]}$

Here, we present a case report of a 24-year-old female patient with a chief complaint of pain and swelling on the right side of palate for 4 months which was diagnosed histopathologically as a ACC.

\section{CASE REPORT}

A 24-year-old female patient complains of pain and swelling on the right side of palate for 4 months. The patient gave a past history of extraction in relation to 18,1 month back. The swelling was sudden in onset and was gradually progressing. On extraoral examination, no apparent abnormality was detected. Intraoral examination reveals a 
diffuse swelling measuring about $3 \mathrm{~cm} \times 4 \mathrm{~cm}$ extending from mesial aspect of 15 to distal aspect of 17 [Figure 1]. Medially, the swelling extends from $0.2 \mathrm{~cm}$ below the gingiva to mid-palatal raphae. The overlying surface is smooth. Right submandibular lymph node enlargement is felt which is around $2 \mathrm{~cm}$ $\times 2 \mathrm{~cm}$ in size, oval in shape, and is non-tender. The computerized tomography showed the expansion of buccal cortical plates in relation to 16 and 17 [Figure 2]. The lesion was provisionally diagnosed as minor salivary gland tumor. An incisional biopsy was performed and was sent for histopathological examination [Figure 3]. $\mathrm{H}$ and $\mathrm{E}$ stained section shows the presence of cells arranged in the form of islands, nests, sheets, and cords. These malignant cells are basaloid in shape [Figures 4 and 5]. The

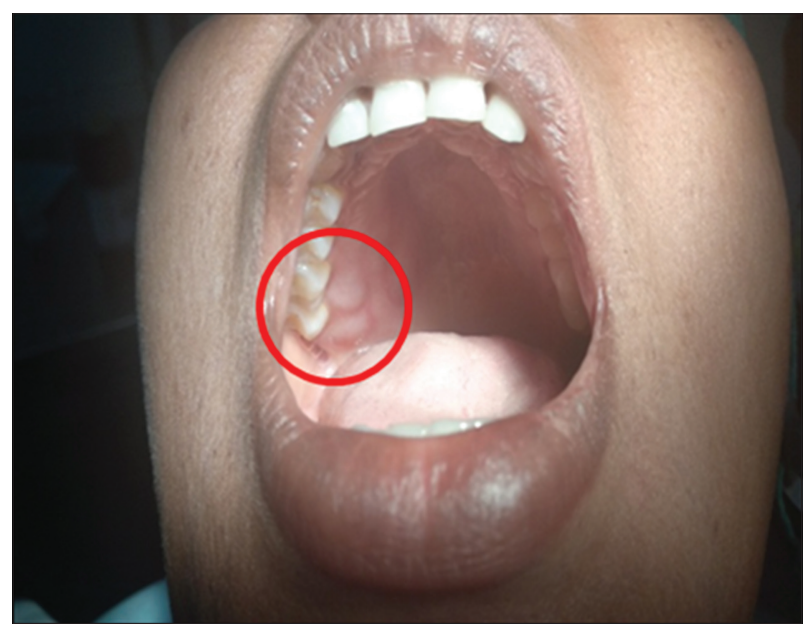

Figure 1: Clinical picture showing a diffuse ill-defined swelling in the right side of the hard palate

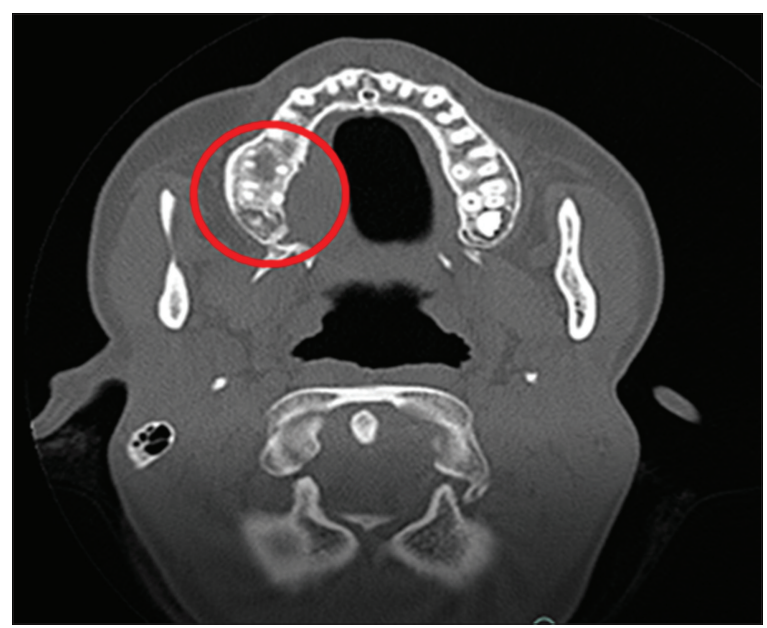

Figure 2: Computerized tomography scan reveals expansion of buccal cortical plates in relation to 16 and 17 tooth region basaloid shape cells exhibited features of nuclear atypia such as nuclear and cellular pleomorphism and nuclear hyperchromatism. The islands show the features of duct-like structures with an inner layer of cuboidal or columnar cells [Figure 6]. There is also the presence of pseudocystic space enclosing of homogeneous eosinophilic material [Figure 7]. The connective tissue exhibited hyalinization and necrosis. Based on histopathological features, the final diagnosis was given as ACC. In the present case, cribriform and tubular types are identified.

\section{DISCUSSION}

The ACC constitutes approximately $29.6 \%$ of minor salivary gland tumor. Most commonly

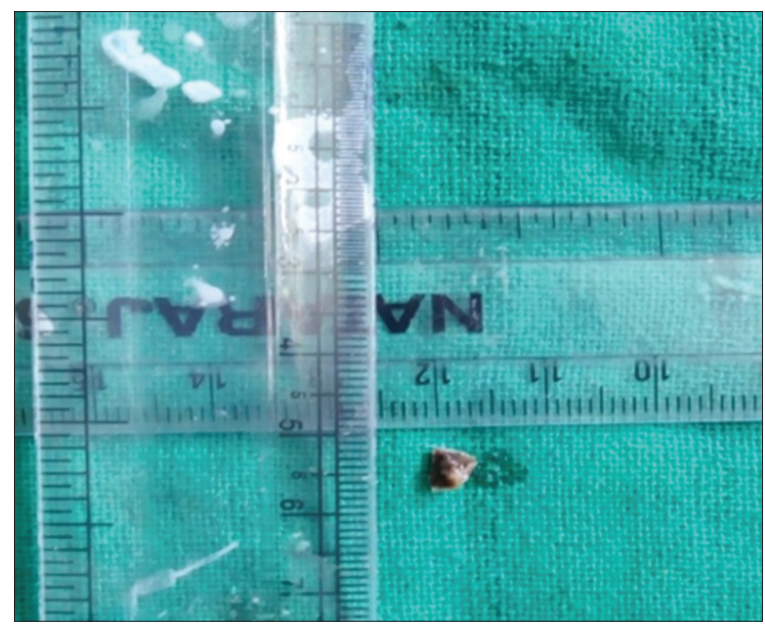

Figure 3: The incisional biopsy specimen measuring about $0.5 \mathrm{~cm} \times 0.5 \mathrm{~cm}$ in size that was sent for histopathological examination

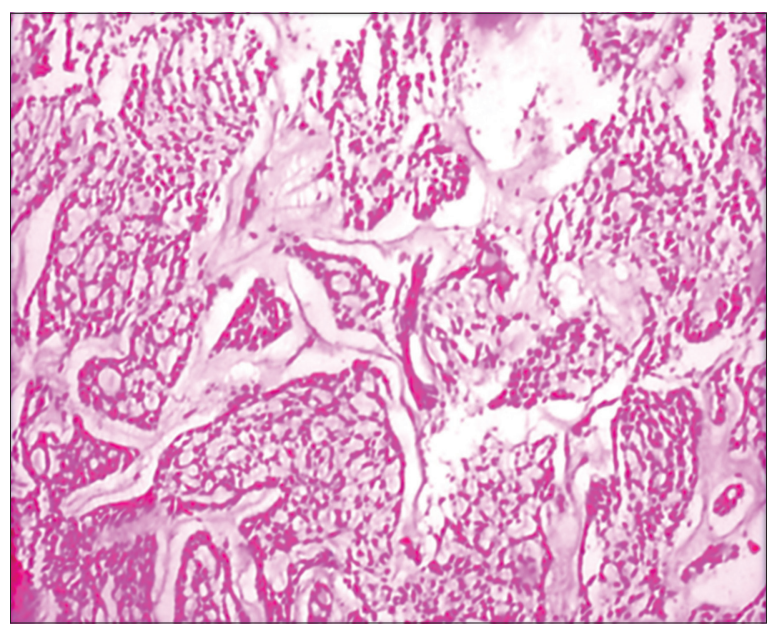

Figure 4: $\mathrm{H}$ and $\mathrm{E}$ stained section shows cells that are arranged in islands, cords, nests, and sheets $(\times 4)$ 


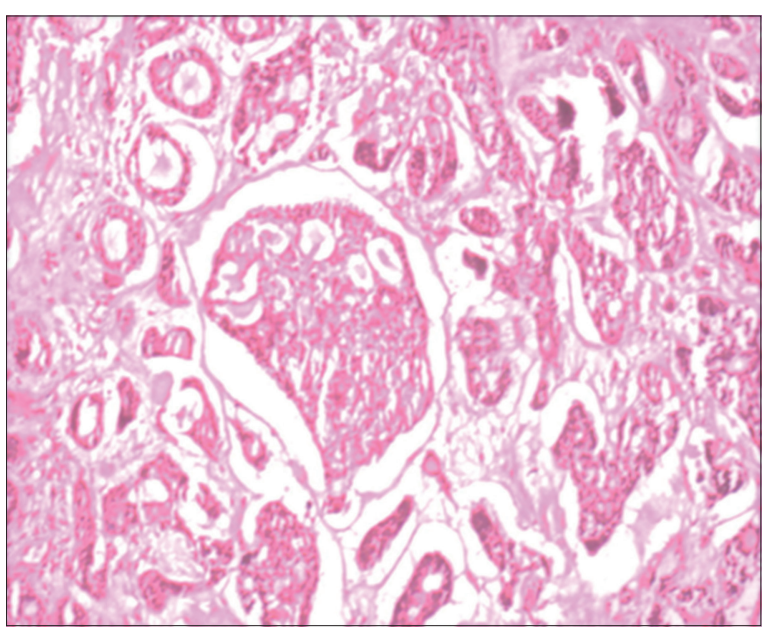

Figure 5: $\mathrm{H}$ and $\mathrm{E}$ stained section shows malignant glandular epithelium with basaloid cells $(\times 10)$

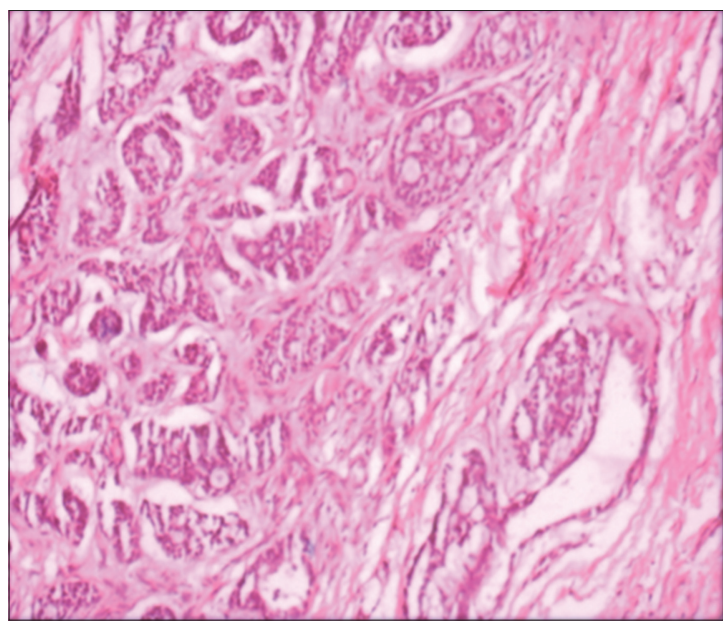

Figure 6: $\mathrm{H}$ and $\mathrm{E}$ stained section shows duct-like structures with an inner layer of cuboidal or columnar cells $(\times 10)$

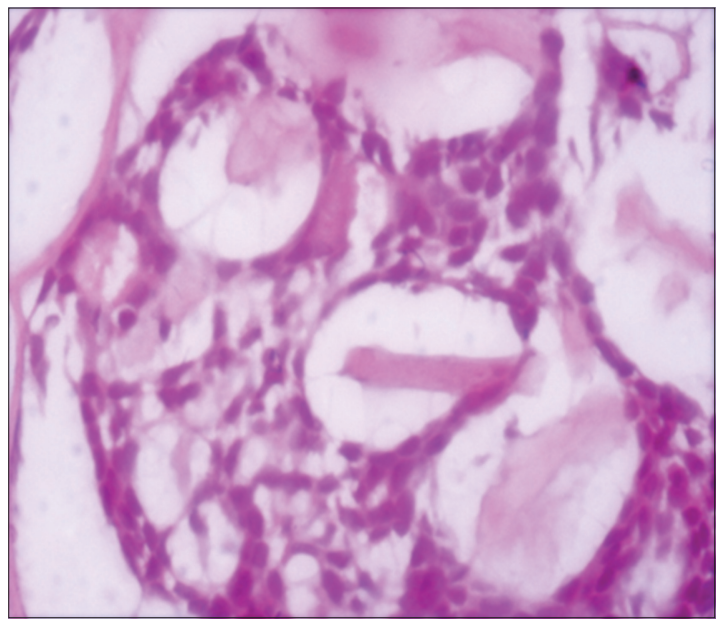

Figure 7: $\mathrm{H}$ and E stained section shows multiple pseudocystic spaces of variable sizes filled with eosinophilic material $(\times 40)$ involved site is palate followed by tongue, floor of mouth, and lip. Other rare locations include the aerodigestive tract, minor salivary glands, lacrimal glands, and adnexal skin glands. Rarely, it may also present as primary intraosseous tumors of the maxilla and mandible. ${ }^{[6]}$

ACC is thought to arise from the mucoussecreting glands. It arises specifically from the intercalated ducts, and electron microscopy shows that it arises from cells that can differentiate into epithelial and myoepithelial cells. ${ }^{[7]}$

ACC is a diagnostic and treatment challenge due to the rarity of the lesion. More studies and further information regarding its clinical behavior as well as treatment modalities and their results are required for ACC. Most cases of ACC are seen in the age of 24-78 years. The age of patients affected with major salivary gland tumors has been shown to be younger (mean 44 years) compared to the age of those who developed tumors of the minor glands (mean 54 years) and shows female predilection (female:male 1.2:1). ${ }^{[8]}$ In the present case, patient was 24-year-old female, which is a common age and gender for ACC. Pain is a common and important finding, occurring early in the course of the disease before there is a noticeable swelling. ${ }^{[8]}$ Among the malignant neoplasms of minor salivary glands, the most common was mucoepidermoid carcinoma $(21.8 \%)$ followed by polymorphous low-grade adenocarcinoma (PLGA) (7.1\%), and ACC was the third most common (6.3\%). ${ }^{[9,10]}$ ACCs of the minor glands have been reported to have a worse prognosis than those of the major salivary glands. ${ }^{[11,12]}$ Since the present case is arising from a minor salivary gland, it is expected to have a poor prognosis. Tumors involving the nose, paranasal sinuses, and maxillary sinus have the worst prognosis as they are usually detected with higher stages at the time of diagnosis. ${ }^{[13]}$

Tumors of minor salivary glands usually have the tendency to infiltrate extraglandular soft tissues and bone, thereby allowing increased dissemination of the tumor. Lymph node involvement is uncommon $(<5 \%$ of cases $)$ and is usually due to contiguous spread rather than lymphatic permeation or embolization. ${ }^{[14]}$

Histologically, ACC of the salivary glands presents with variable combinations of the three main growth patterns, i.e., cribriform, tubular, and solid. In the present case, a combination of cribriform and tubular is seen. The cribriform is the most 
characteristic in which the basaloid cells constitute the major cell population, showing mild nuclear pleomorphism and few or no mitoses; in the solid variant, these cells usually show a more pleomorphic appearance and mitoses are more commonly found. ${ }^{[15]}$

Salivary gland ACC is graded using a specific three-tier grading system, originally proposed by Szanto et al. in 1984, which is solely based on the main type of growth pattern presenting the tumor. Grade 1 ACCs are well differentiated and composed of tubular and cribriform patterns without solid components, Grade 2 ACCs are characterized by a pure cribriform pattern or mixed with $<30 \%$ of solid areas, and Grade 3 ACCs are tumors with a marked predominance of the solid pattern. The prognostic factor of ACC depends on the site of the tumor, stage of the tumor, the presence of perineural invasion, and grade of the tumor. Tubular and cribriform subtypes have a better prognosis than solid subtypes. Many authors described poor prognosis for tumors of the minor salivary glands, due to early local infiltration and invasion of surrounding tissue and bone. ${ }^{[15]}$

Other special stains that are used to demonstrate the pseudocysts are periodic acid Schiff reagent and Alcian blue. On immunohistochemical analysis, epithelial cells are positive for carcinoembryonic antigen and epithelial membrane antigen. Duct lining cells are positive for C-kit (CD117) and myoepithelial cells are positive for S-100 protein, calponin, p63, smooth muscle actin, and myosin. Expression of S-100, glial fibrillary acidic protein, and neural cell adhesion molecule have been correlated with the presence of perineural invasion. P53 mutations appear to be involved with tumor progression and recurrence. ${ }^{[16]}$ Hypermethylation of the promoter region of the 16 gene was associated with higher histologic grades of malignancy. Microarrays and comparative genomic hybridization have been used to identify candidate genes for ACC. ${ }^{[16]}$

\section{CONCLUSION}

ACC is an uncommon salivary gland malignancy. It is unique for its peculiar histopathological features and tendency for recurrence. Prognostic factors of ACC are the anatomic site, histologic subtypes, and metastasis. ACC is sometimes associated with a poor prognosis. Therefore, early clinical and histopathological diagnosis, prompt treatment, and long-term follow-up are essential in the management of this tumor.

\section{REFERENCES}

1. Chundru NS, Amudala R, Thankappan P, Nagaraju CD. Adenoid cystic carcinoma of palate: A case report and review of literature. Dent Res J (Isfahan) 2013;10:274-8.

2. Matsuba HM, Spector GJ, Thawley SE, Simpson JR, Mauney M, Pikul FJ, et al. Adenoid cystic salivary gland carcinoma. A histopathologic review of treatment failure patterns. Cancer 1986;57:519-24.

3. Spiro RH, Huvos AG, Strong EW. Adenoid cystic carcinoma: Factors influencing survival. Am J Surg 1979;138:579-83.

4. Marx RE, Stern D. Oral and Maxillofacial Pathology: A Rational for Diagnosis and Management. $2^{\text {nd }}$ ed., Vol. 13. Chicago: Quintessence; 2002. p. 550-3.

5. Szanto PA, Luna MA, Tortoledo ME, White RA. Histologic grading of adenoid cystic carcinoma of the salivary glands. Cancer 1984;54:1062-9.

6. Yaga US, Gollamudi N, Mengji AK, Besta R, Panta P, Prakash B, et al. Adenoid cystic carcinoma of the palate: Case report and review of literature. Pan Afr Med J 2016;24:106.

7. Ellis GL, Auclair PL, Gnepp DR. Adenoid Cystic Carcinoma, Surgical Pathology of Salivary Glands. Vol. 18. Philadelphia, PA: WB Saunders; 1991. p. 333-46.

8. Neville BW, Damm D, Allen CM, Bouquot JE. In: Neville BW, editor. Salivary Gland Pathology: Oral and Maxillofacial Pathology. Vol. 11. 2009. p. 495-7.

9. Buchner A, Merrell PW, Carpenter WM. Relative frequency of intra-oral minor salivary gland tumors: A study of 380 cases from northern California and comparison to reports from other parts of the world. J Oral Pathol Med 2007;36:207-14.

10. Pour MS, Zarei MR, Chamani G, Rad M. Malignant salivary glands tumors in Kerman province: A retrospective study. Dent Res J 2007;4:4-10.

11. Nascimento AG, Amaral AL, Prado LA, Kligerman J, Silveira TR. Adenoid cystic carcinoma of salivary glands. A study of 61 cases with clinicopathologic correlation. Cancer 1986;57:312-9.

12. Dal Maso M, Lippi L. Adenoid cystic carcinoma of the head and neck: A clinical study of 37 cases. Laryngoscope 1985;95:177-81.

13. Kokemueller H, Eckardt A, Brachvogel P, Hausamen JE. Adenoid cystic carcinoma of the head and neck a 20 years experience. Int J Oral Maxillofac Surg 2004;33:25-31.

14. Allen MS Jr., Marsh WL Jr. Lymph node involvement by direct extension in adenoid cystic carcinoma. Absence of classic embolic lymph node metastasis. Cancer 1976;38:2017-21.

15. Choudhary K, Beena VT, Rajeev R, Manju S, Sivakumar R, Padmakaumar SK. Adenoid cystic carcinoma of the hard palate: A case report with a review of the literature on therapeutic and prognostic aspects. Ind $J$ Oral Sci 2012;3:113.

16. John W, Toshitaka N. Diseases of the salivary glands. In Barnes L, editor. Surgical Pathology of the Head and Neck. $3^{\text {rd }}$ ed. New York: Informa Health Care; 2009. p. 552-7. 